\title{
Severe phosphoribosylpyrophosphate synthetase superactivity
}

INSERM

\section{Source}

INSERM. (1999). Orphanet: an online rare disease and orphan drug data base. Severe phosphoribosylpyrophosphate synthetase superactivity. ORPHA:411543

Severe phosphoribosylpyrophosphate (PRPP) synthetase superactivity is the severe and early-onset form of PRPP synthetase superactivity (see this term), an X-linked disorder of purine metabolism associated with hyperuricemia and hyperuricosuria, that is characterized by urolithiasis, gout and neurodevelopmental anomalies. 